\title{
The Role of MiR-132 in Regulating Neural Stem Cell Proliferation, Differentiation and Neuronal Maturation
}

\author{
Dong Chen Siyuan Hu Zhong Wu Jie Liu Shaohua Li \\ Department of Orthopedics, Shanghai Tenth People's Hospital, Tongji University School of Medicine, \\ Shanghai, China
}

\section{Key Words}

Mir-132 - Neural stem cells $\bullet$ Cell proliferation $\cdot$ Differentiation $\bullet$ Neuronal maturation $\bullet$ Notch pathway • ERK pathway

\begin{abstract}
Background/Aims: microRNAs are of vital importance in neural development. As a brainspecific miRNA, miR-132 has been well studied in mature neurons. However, its role in neural stem cells (NSCs) remains unclear. In this study, we investigated the role of miR-132 in regulating NSCs proliferation, differentiation and neuronal maturation. Methods: NSCs were obtained from fetal mice spinal cord. Proliferation, cell cycle, cell apoptosis, cell motility were measured through CCK-8, BrdU, AnnexinV-FITC/PI and migration assay respectively. The expression of synaptic proteins and ERK1/2 pathway were detected by western blot. The inactivation of Notch pathway was checked using qPCR. The neurite outgrowth was recorded using Image J software and Neuron J software. Dendritic length was further analyzed through sholl analysis. Fate determination of NSCs, developmental synapse formation was assessed by immunostaining. Results: miR-132 negatively regulated NSCs proliferation by affecting the cell cycle and promoting apoptosis. Inactivated Notch-Heslpathway was observed in miR-132 overexpression cells. miR-132 was significantly increased in differentiating NSCs following activation of ERK1/2 pathway. miR-132 could impair neuronal differentiation but promote glial cell differentiation by regulating Mecp2 expression. miR-132 was implicated in neurite outgrowth but slightly inhibited postsynaptic PSD-95 expression. The differentiated neurons exhibited normal electrophysiological characteristics, and already interacted with other neurons to form synaptic-like structures. Conclusion: miR-132 was demonstrated as a negative regulator for NSCs self-renewal, neuronal differentiation but promoted glial cell differentiation and neurite outgrowth.
\end{abstract}




\section{Cellular Physiology Cell Physiol Biochem 2018;47:2319-2330

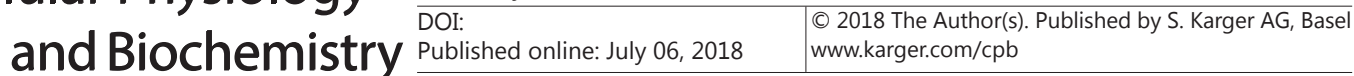 \\ Chen et al.: The Role of MiR-132 in NSCs}

\section{Introduction}

Neural stem cells (NSC) can proliferate and give rise to neuronal and glial lineages [1]. Theoretically, NSCs can be used in treating spinal cord injury (SCI) and other neurological disorders such as Alzheimer's disease [2], since differentiated neurons have the potential to replace damaged neurons and reconstruct neural circuits. However, the results are disappointing. NSCs transplanted into injured spinal cord hardly survive due to the ischemiahypoxia microenvironment. Moreover, only few NSCs differentiate into neurons, the majority of them become glial cells. Ultimately, excessive glial scar can form physical barrier that hinder nerve growth [3].

Neurogenesis is a complicated process referring to neural stem cell proliferation (selfrenewal), differentiation (fate specification), migration, neuronal maturation and functional integration. The whole process is regulated by the dynamic interplay between transcription factors, microRNAs (miRNA) and cell-niche signaling. Uncovering the role of molecules and signaling pathways involved in neurogenesis is vital for the development of effective therapeutic approaches in traumatic and degenerative neurological disorders [4].

MicroRNAs (miRNA) comprise a family of small, non-coding RNA molecules that are involved in a lot of biological functions, including neural development, tumor metastasis, cell proliferation, differentiation and apoptosis. Most miRNAs can negatively regulate expression of downstream target gene by directly binding to the 3'-untranslated region (3'-UTR) of a target miRNA leading to degradation of mRNA or transcription inhibition. However, miRNAs can also positively regulate gene expression by targeting gene promoter binding $[5,6]$. Previous studies have demonstrated that miRNAs almost function in the whole process of neural development. For instance, miR-125b, let-7 influence the NSC self-renewal. miR-9, miR-124, miR-381 regulate neuronal differentiation. miR-219, miR-338 are required for glial cell differentiation and miR-34a is involved in neural differentiation, cell morphology and synapse formation [7-9]. Moreover, miRNAs have been reported to regulate several signaling pathways in neural development. miR-124a and miR-9 have been shown to target several components of the Notch signaling cascade [10], interaction of miR-9 with the Notch signaling pathway is also found in Drosophila [11]. miR-125a/b and miR-135b could target BMP/TGF $\beta$ signaling cascade to promote neural induction $[12,13]$. miR-135a is proved to delimits the dorsoventral extent of dopaminergic progenitors by directly interfering with Wnt signaling [14].

miR-132 is highly expressed in the central nervous system and has been well studied in differentiated neurons. Numerous studies have highlighted its role in synaptic plasticity, neurite outgrowth and neuronal morphogenesis [15-17]. However, few studies focus on its role in NSCs proliferation, migration, cell fate specification as well as neuronal maturation. In our study, we extracted NSC from fetal mouse spinal cord and investigated the effect of miR-132 on NSC self-renewal, sphere formation, differentiation, and neuronal maturation. In addition, we explored the potential target gene methyl-CpG-binding protein 2 (MECP2) of miR-132 in the process of NSC differentiation. The electrophysiological characteristics and functional relevance of new born neurons derived from fetal spinal cord NSCs were analyzed. The ERK1/2 signal pathway causing increased expression of miR-132 during differentiation, and Notch signaling maintaining stem cell proliferation, were also studied.

\section{Materials and Methods}

\section{Cell culture and differentiation}

Neural stem cells were obtained from 13.5 days of fetal mice spinal cord and cultured in growth medium with the 2\% N2 (Gibco), 1\%B27 (R\&D), bFGF 20ng/ml (R\&D), EGF 20ng/ml (R\&D). The cells were growing to form neurospheres. The cell density was adjusted to $5^{*} 10^{5} / \mathrm{ml}$ and inoculated on 24 -well plate $(0.5 \mathrm{ml}$ per well). The medium was changed to differentiation medium containing $2 \% \mathrm{~N} 2$ and $0.5 \% \mathrm{FBS}$ (Gibco) after the cells were basically cultured for $1-2 \mathrm{~d}$. The samples were collected at 1, 3,5, 7 days after differentiation. 


\section{$\begin{array}{ll}\text { Cellular Physiology } & \text { Cell Physiol Biochem 2018;47:2319-2330 } \\ \text { DOI: } & \text { 2018 The Author(s). Published by S. Karger AG, Basel }\end{array}$ \begin{tabular}{l|l} 
and Biochemistry Poblished online: July 06, 2018 & $\begin{array}{l}\text { O } 2018 \text { The Author(s). Published by S. Karger AG, Basel } \\
\text { www.karger.com/cpb }\end{array}$ \\
\cline { 1 - 2 }
\end{tabular} \\ Chen et al.: The Role of MiR-132 in NSCs}

Proliferation assays

Cell proliferation was measured by Cell Counting Kit-8 (cck-8) assay (dojindo). 10ul CCK-8 was added to each well, and then incubated in the incubator for 2 hours and further transferred to the 96-well plate for determination of the absorptivity at $450 \mathrm{~nm}$. Proliferation rates were evaluated at 1, 3,5, 7 days after treatment.

Transfection of miR-132 mimics and inhibitor

After 7 days culture, NSCs were digested using trypsin (ProSpec-Tany) and re-suspended by differentiation medium. The cells were incubated on 6-well plate, $2 \mathrm{ml}$ suspension was added per well. 15ul POL03000 transfection reagent was mixed with 200ul DMEM/F12 medium, meanwhile 5ul miR-132 mimics was mixed with 200ul DMEM/F12, for $5 \mathrm{~min}$ at room temperature. Follow that, mixed the 2 solutions and incubated for $15 \mathrm{~min}$, then dripped the transfection reagent mixture into cell suspension. Samples were collected $24 \mathrm{~h}$ after transfection.

\section{Western blot}

Cell lysates were separated in 10\% SDS-PAGE gels and blotted on PVDF membranes (100v, 120min). The membranes were blocked with TBST solution containing 5\% skim milk. Primary Anti-bodies Mecp2, ERK, p-ERK, PSD95 and Synapsin I (abcam) were incubated overnight, after that the membranes were washed with TBST for 3 times and incubated with secondary anti-body at room temperature for 1hour. Signals were detected using ECL (Millipore).

\section{Immunostaining}

Cells were fixed with 4\%PFA for 15-30min at room temperature. After washing with PBS 2-3 times, covered with $4 \%$ BSA solution containing $0.1 \%$ triton-100 at room temperature for $1 \mathrm{~h}$, and then incubated overnight with 4\% BSA-diluted primary antibodies Nestin, Tuj1, GFAP, MAP-2,PSD95, Synapsin I (dilution ratio 1: 50) (abcam). The samples were removed from $4{ }^{\circ} \mathrm{C}$ on the second day and reheated at room temperature for about 30 minutes, then incubated with second antibody with fluorescent label (sigma) at room temperature for $1 \mathrm{~h}$. Then discarded the solution and washed with PBS for 3-5 times. Nuclei were stained with DAPI (sigma).

\section{Analysis of neurite outgrowth}

Neurite number and dendritic length were determined to evaluate neuronal maturation. Neurites of labeled cells were manually traced with Image J software and the Neuron J. The averaged neurite number was recorded and dendritic length was analyzed using sholl analysis.

\section{Statistical analysis}

The relative intensities of protein bands were analyzed with the Image Lab (Bio-Rad Laboratories). Data are shown as mean \pm SD from three independent experiments. Results were compared using Student's Test or one-way ANOVA. Statistical analysis was performed with GraphPad Prism 7 software.

\section{Results}

miR-132 was highly expressed in central nervous system

The Neural stem cells (NSC) isolated from fetal mice spinal cord could proliferate and form neurospheres (Fig. 1A-B). The undifferentiated cells were identified by NSC-specific marker Nestin (Fig. 1C-D). The differentiated NSCs could express Tuj1 and GFAP which were the markers for neurons and glial cells respectively (Fig. 1E-F). In the process of differentiation, NSCs showed decreased expression of Nestin whereas Tuj1 and GFAP were increased (Fig. 1G). Finally, most cells differentiated into glial cells while only a small portion of them became neurons.

To determine the expression level of miR-132 in central nervous system, qPCR analysis was performed in various types of cells including the NSCs, neuron cells (NC) and epithelial cells (EC). miR-132 was highly expressed in NSCs and neurons compared to epithelial cells 


\section{Cellular Physiology and Biochemistry

(Fig. 1H). Moreover, miR-132 was significantly increased during embryonic development, and there was no obvious difference in miR-132 expression between spinal cord, cerebral cortex and hippocampus (Fig. 1I). During induced differentiation in vitro, miR-132 was gradually increased and reached the highest level at $7^{\text {th }}$ day of differentiation (Fig. 1J).

miR-132 abrogated NSCs proliferation and migration

To explore the role of miR-132 in NSC proliferation and migration, negative control RNAs, miR-132 mimic and miR-132 inhibitor were transfected into NSCs respectively (Fig. 2AB). Results analysis pointed to the conclusion that miR-132 can inhibit cell proliferation by affecting the cell cycle and promoting apoptosis (Fig. 2CF). Moreover, miR-132 abrogated cell motility (Fig. 2G).

miR-132 impaired neural differentiation but promoted glial cell differentiation

We transfected the miR-132 mimics into NSCs and induced differentiation, the Tuj1 positive and GFAP positive cells were assessed separately by immunostaining. As shown in Fig. 3A-E, miR-132 overexpression led to enlarged GFAP positive cells and reduced Tuj1 positive cells. Further, we predicted the miR-132 target genes at miRTarBase and TargetScan. Among all the candidates, Mecp2 aroused our interest. In addition, Mecp2 showed the most obvious reduction in protein expression level after miR-132mimics transfection (Fig. 3F).

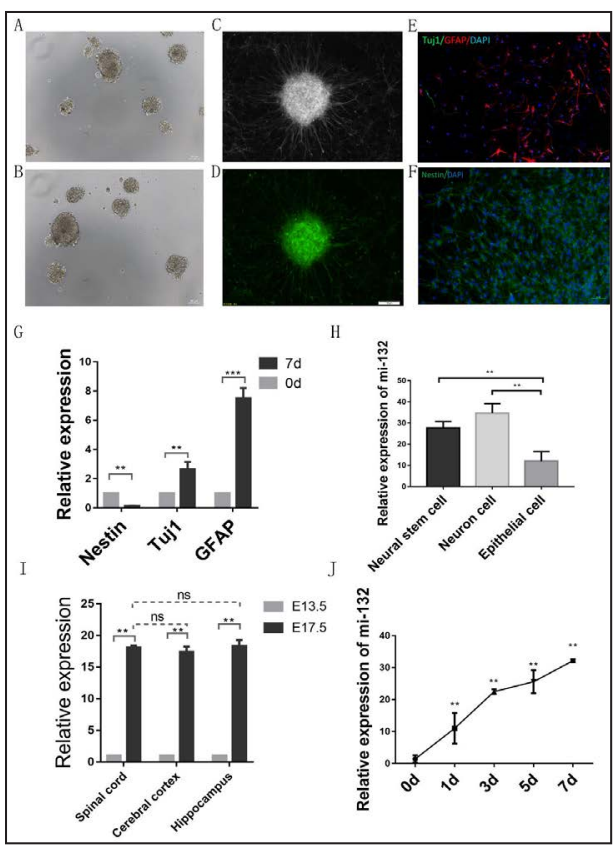

Fig. 1. miR-132 was increasing during differentiation. NSCs extracted from fetal mice spinal cord could self-renewal and form neurospheres (A-B). Cell identification by immunostaining (C-F). Cell specific markers changed during differentiation $(G)$. Relative miR-132 expressions in different cell types were measured by qRT-PCR (H). Relative miR-132 expressions during embryonic development (I). Relative miR132 expressions during differentiation (J). *, $\mathrm{P}<0.05$; **, $\mathrm{P}<0.01 ;{ }^{* * *}, \mathrm{P}<0.001$ compared with control group. Mecp2 with complementary sequences and was verified as a miR-132 target gene (Fig. 3G). Moreover, we also found decreased Mecp2 expression in NSCs transfected with miR-132 mimics (Fig. 3H) and this was further confirmed by immunostaining (Fig. 3I).

\section{miR-132 directly target Mecp2 during NSC differentiation}

To further confirm whether miR-132 directly suppressed the Mecp2 expression in the process of NSC differentiation, Mecp2 Knock-Down Lentivirus was constructed (Fig. 4A-C) and transfected into NSCs (Fig. 4D). As shown in Fig. 4E, fluorescence intensity was dramatically reduced in Mecp2-KD cells compared to NC group. Reduced tuj1 positive cells and increased GFAP positive cells were found in Mecp2-KD group (Fig. 4F). This was consistent with the result obtained in miR-132 overexpression NSCs. In addition, miR-132 overexpression led to decreased Mecp2 expression. Furthermore, Mecp2 was a target gene of miR-132 with complementary sequences of 3'UTR. These combined evidence confirmed that Mecp2 expression was directly regulated by miR-132.

miR-132 promoted neurite outgrowth and differentiated neurons formed synaptic-like structures

Differentiated neurons were gradually maturing with dendritic spine and synapse formation. We investigated whether miR-132 involved in neuronal maturation. miR-132 
Fig. 2. miR-132 impaired NSCs proliferation by affecting the cell cycle and promoting apoptosis. Relative miR-132 expression after mimics and inhibitor transfection (A-B). CCK-8 was performed to assess cell proliferation (C). Cell cycle assay (BrdU) (D-E). Analysis of cell apoptosis (AnnexinVFITC/PI) (F). Migration assay to assess cell motility (G).
Fig. 3. miR-132 impaired neuronal differentiation but promoted glial cell differentiation. Immunostaining was performed to separately detect Tuj1 positive and GFAP positive cells after miR132 mimic transfection (A-E). Relative expression of predicted target genes after miR-132 mimics and inhibitor transfection (F). miR-132 could bind to 3'UTR of Mecp2 with complementary sequences $(G)$. Mecp2 was decreased after Mir-132 mimics transfection confirmed by fluorescence intensity and WB (H-I).
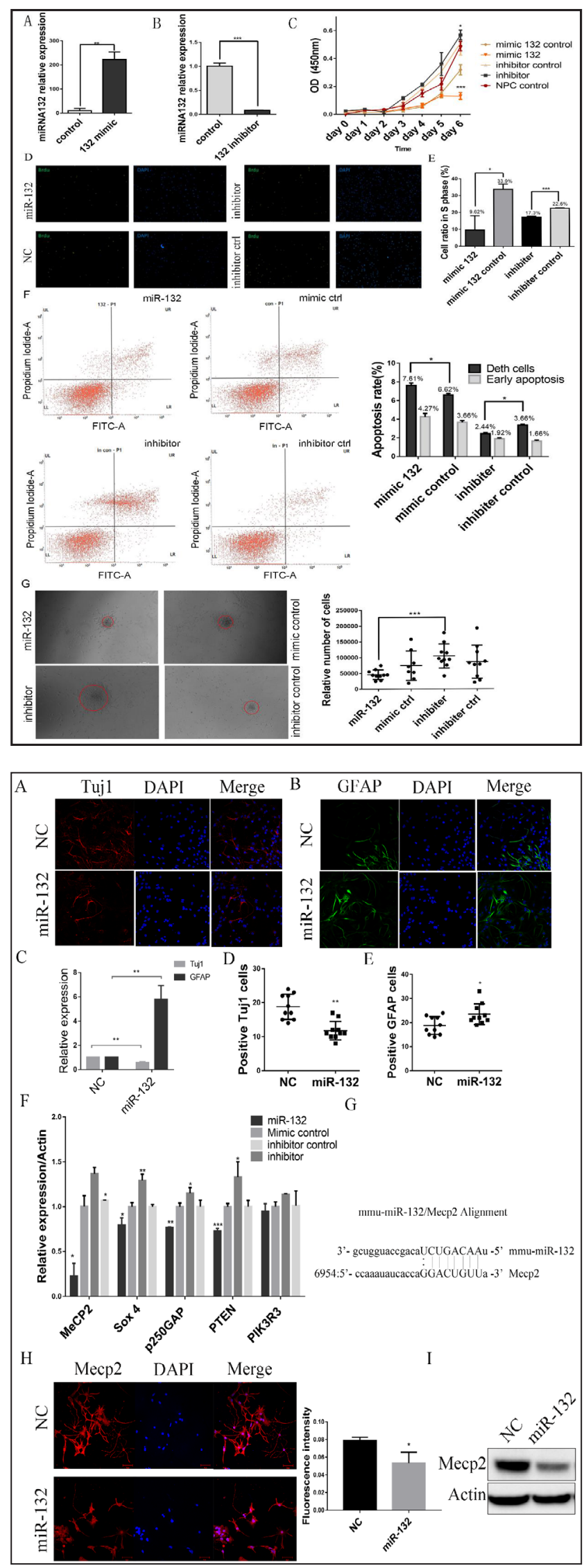


\section{Cellular Physiology and Biochemistry

mimics was transfected 3 days after differentiation. We found that miR132 promoted neurite outgrowth with increased neurite number and dendritic length (Fig. 5A-C). At 14th day of differentiation, the neurons were stained with MAP-2, these differentiated neurons connected together (Fig. 5D), and formed synaptic-like structures (Fig. 5E). The evoked AP was recorded by whole-cell current clamp recordings (Fig. 5F), but the action potential duration- $\mathrm{APD}_{50}$ was much longer than neurons derived from stem cells in the subventricular Zone. Neurotransmitters such as ChAT and Glu that highly expressed in spinal cord were confirmed by immunostaining (Fig. 5G). However, miR-132 slightly inhibited postsynaptic protein PSD-95 expression while it did not change the presynaptic protein Synapsin I expression (Fig. 5H).

\section{Activated ERK1/2 signaling led} to increased miR-132 expression during NSCs differentiation

Previous studies have demonstrated that ERK1/2 signaling pathway is crucial for cell

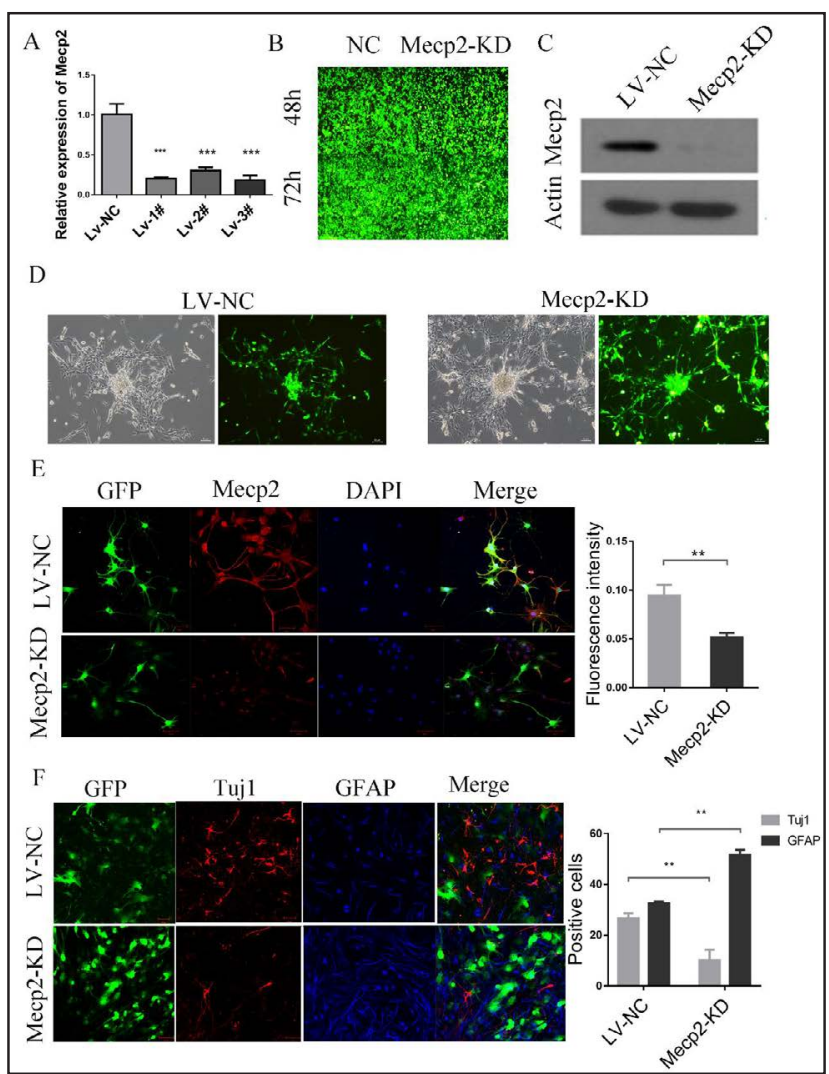

Fig. 4. miR-132 directly target Mecp2 during NSC differentiation. Construction of Mecp2-KD Lentivirus (A-C). The lentivirus transfected into NSCs (D). Mecp2 expression was significantly decreased after transfection (E). Decreased Tuj1 positive cells and increased GFAP positive cells were found in Mecp2-KD group (F). differentiation. Since miR-132 was increased in differentiating NSCs, we wondered whether ERK1/2 caused the up-regulation of miR-132. The expression of ERK1/2 and p-ERK1/2 were detected at different time points of differentiation, according to WB results, p-ERK1/2 was increased and maintained the high level of expression throughout the whole process (Fig. 6A-C). Similar results were obtained in expression of miR-132. Next, we investigated the relationship between miR-132 and ERK1/2 pathway. No obvious change was found in NSCs transfected with miR-132 mimics or miR-132 inhibitor (Fig. 6D). On the other hand, when spontaneous ERK1/2 activity was suppressed by SCH772984 (an inhibitor of MAPK/ERK kinase), miR-132 was dramatically decreased (Fig. 6E-F). Interestingly, blocking ERK1/2 increased PSD-95 expression (Fig. 6G). Further, immunostaining revealed that inactivated ERK1/2 pathway caused impaired neuronal differentiation (Fig. 6H-I). These results suggested that miR-132 expression was regulated by ERK1/2 pathway, but with opposite effects on fate determination of NSCs. It reminded us that the activation of ERK1/2 pathway leading to increased miR-132 expression might be a trigger to initiate differentiation, then miR-132 might switch to interact with other pathways.

miR-132 did not affect neurosphere formation of NSCs but inhibited cell proliferation through Notch-Hes1 pathway

Neurosphere formation was one of most important stem cell characteristics. According to our results, miR-132 and Mecp2 appeared to have no effect on sphere formation (Fig. 7A). Mecp2-KD promoted cell proliferation (Fig. 7B), in contradiction with the result we 
Fig. 5. miR-132 promoted neurite outgrowth and differentiated neurons formed synaptic-like structures. miR-132 mimics treatment caused increased neurite number. Image J and Neuron J were used to assess neuronal maturation (neurite number and dendritic length) (A-C). Differentiated neurons connected together and formed synaptic-like structures (DE). The evoked AP was recorded by whole-cell current clamp recordings (F). Neurotransmitters (ChAT and Glu) that highly expressed in neurons in spinal cord were confirmed by immunostaining (G). miR-132 slightly inhibited postsynaptic protein PSD95 expression while it did not change the presynaptic protein Synapsin I expression $(\mathrm{H})$.

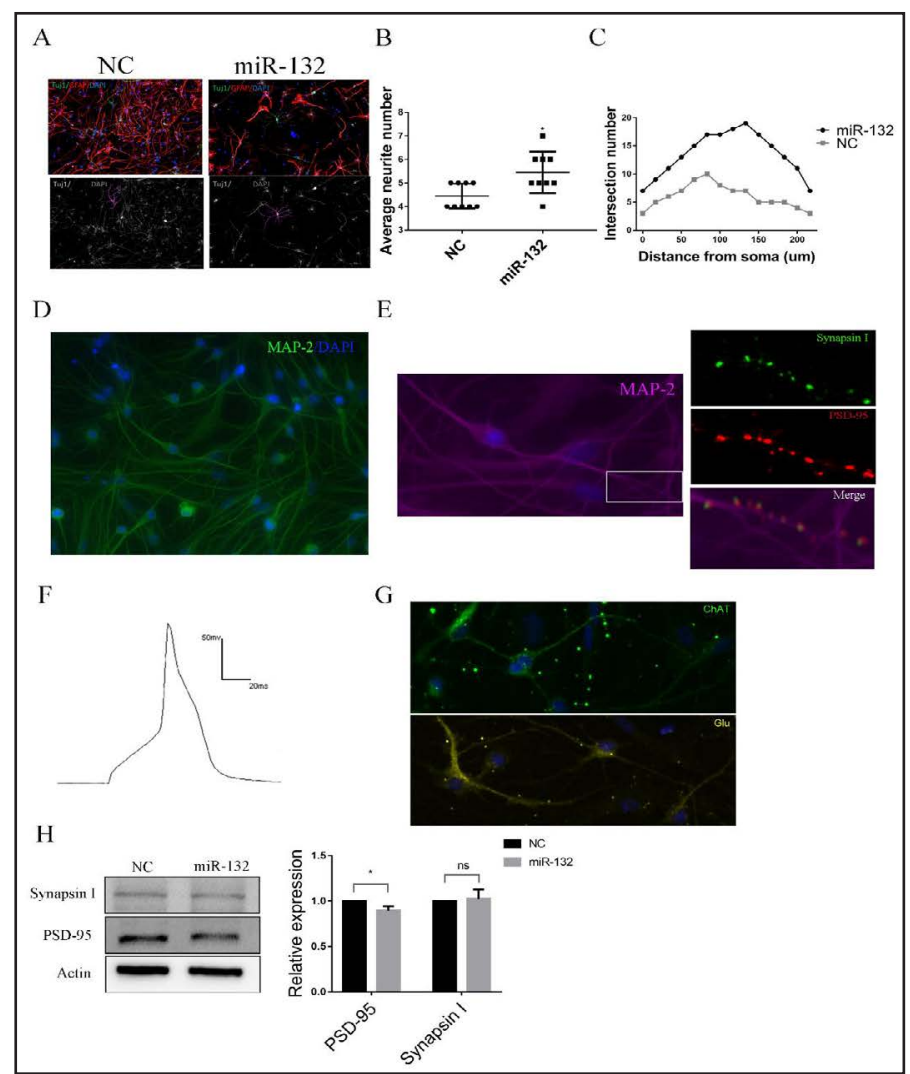

Fig. 6. miR-132 was regulated by ERK1/2 pathway. WB was performed to determine phosphorylated ERK1/2 expression during differentiation (A-C). Phosphorylated ERK1/2 expression after mimics and inhibitor transfection (D). SCH772984 could effectively suppress ERK1/2 pathway (E). Relative miR-132 expression after SCH772984treatment (F). Relative PSD-95 expression after SCH772984 treatment (G). Immunostaining was performed to assess the role of ERK1/2 pathway in NSCs fate determination (H-I).

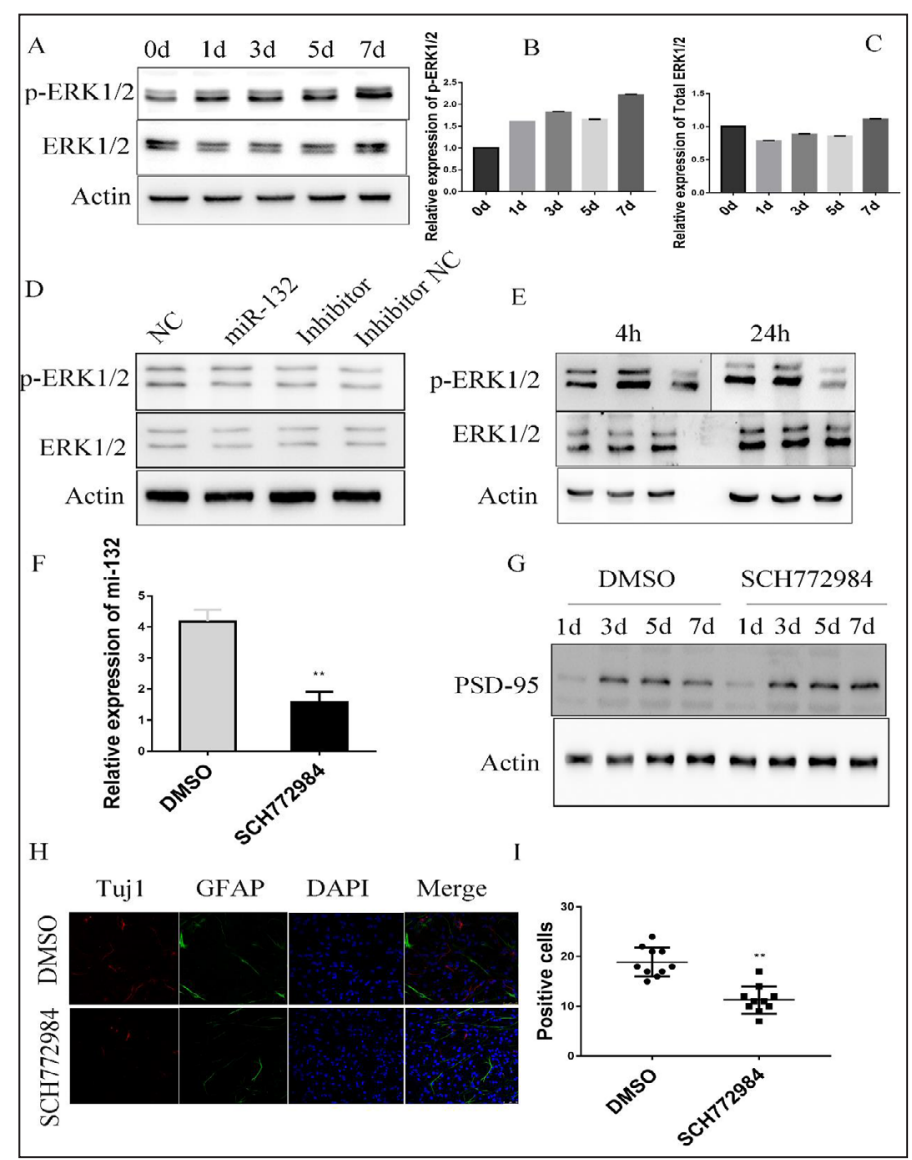




\section{Cellular Physiology and Biochemistry

obtained in overexpression of miR-132 (Fig. 2C). Notch signal pathway has been proved to play a role in maintaining NSCs in undifferentiated state. It is known that Notch pathway affect cell proliferation by regulating downstream targeted genes, such as Hes1. Although not being a predicted target of miR-132, down-regulation of miR-132 led to increased Hes1 expression (Fig. 7C). Increased Hes1 expression caused by miR-132 inhibitor was partly rescued by utilizing R04929097 (Notch signaling inhibitor) (Fig. 7D).

\section{Discussion}

Many studies have demonstrated the important role of miR-132 in nervous system. miR-132 has been reported to be involved in neuronal morphogenesis, dendritic growth, synapse formation, physiological rhythm and drug addiction [18-22]. Reduced miR-132 expression is also implicated in several neurodegenerative disease such as Alzheimer's disease (AD) and Parkinson's disease (PD)[23, 24]. Besides its numerous roles in neuronal development and related diseases, it has been shown that miR-132 also mediates inflammatory processes [25]. Therefore, miR-132 is recently regarded as a 'NeurimmiR' that regulates both neuronal and immune functions, plays a role of cross-talk between two systems [17]. However, most research have focused on miR-132 functions in cultured neurons. Yet, few studies have investigated its functions in NSCs proliferation, migration, and differentiation. In this study, we showed that miR-132 was highly expressed in NSCs and overexpression of miR-132 could block Notch-Hes1 pathway to inhibit cell proliferation. It also affected cell cycle, promoted apoptosis and abrogated cell motility but with no effect on sphere formation. More than that, increased miR-132 following ERK signaling activation inhibited neuronal differentiation by regulating Mecp2 expression. miR-132 could promote neurite outgrowth of differentiated neurons, and these neurons formed synaptic-like structures at $14^{\text {th }}$ day of differentiation.

Consistent with previously studies, we observed highly expressed miR-132 in NSCs and neurons. It is well documented that miR-132 play crucial roles in the regulation of cell proliferation and migration. Park JK et al. have demonstrated that miR-132 could promote the proliferation of pancreatic cancer cells [26]. Conversely, miR-132 has been proved to inhibit proliferation and migration of ovarian cancer cells [27]. Luo J et al. have showed that miR-132 negatively regulate the proliferation of lung cancer cells [28]. Clovis YM et al. have 


\section{Cellular Physiology Cell Physiol Biochem 2018;47:2319-2330 \\ \begin{tabular}{l|l} 
and Biochemistry Published online: July 06, 2018 & $\begin{array}{l}\text { (c) } 2018 \text { The Author(s). Published by S. Karger AG, Basel } \\
\text { www.karger.com/cpb }\end{array}$ \\
\hline
\end{tabular} \\ Chen et al.: The Role of MiR-132 in NSCs}

reported that miR-132 impair radial migration of neurons by targeting Foxp2[29]. These results are well aligned with our findings.

Notch signaling pathway is associated with delayed neurogenesis, increased gliogenesis and is crucial for maintaining neural stem cells in an undifferentiated state [30]. Salta E et al. have noticed that miR-132 dampens radial glial (embryonic neural stem cells) proliferation but promotes oligodendrocyte differentiation by fine tuning Notch signaling [31]. Decreased expression of miR-132 promotes neuronal differentiation of embryonic stem cells (ESC)[32], that was in line with the result we obtained in NSCs. Overexpression of miR-132 showed impaired neuronal differentiation and enhanced glial differentiation. Meanwhile, miR-132 overexpression resulted in decreased Mecp2 in this process. In addition, Mecp2-KD also led to decreased number of neurons but increased glial cells. Furthermore, miR-132 could bind to 3'UTR of Mecp2 with complementary sequences [33]. Those combined results demonstrated that miR-132 inhibited neuronal differentiation by regulating Mecp2 expression in NSCs.

miR-132 is also implicated in neural plasticity. In miR-132-knockout mice, miR-132 could influence synaptic transmission and plasticity [34]. More than that, miR-132 could regulate axonal growth by targeting Rasa1 [35]. Yoshimura et al. have pointed out that miR132 negatively regulated synapse maturation by indirectly down-regulating PSD-95 [36]. Besides, we also found increased neurite number and longer dendritic length in newborn neurons with highly expressed miR-132. Dendritic and axon growth, neuronal plasticity as well as synapse formation are all involved in neuron maturation. It is interesting that miR132 promoted neurite outgrowth while suppressing synapse protein expression.

miRNAs could simultaneously regulate multiple targets [37]. Several studies have confirmed that MeCP2, Sox4, PTEN, PIK3R3, p250GAP are targets of miR-132 [33, 38-41]. However, in different cell types, targets of miRNAs might change and even the same miRNA could have the opposite effect on cell behaviors. For example, positive effect of miR-132 on dendritic growth and arborization of neurons by repressing p250GAP expression [42], is in contradiction with the observation that MeCP2 also facilitates neuronal maturation, since Mecp2 and p250GAP are both reported target genes of miR-132 [43]. Accumulating evidence suggest that miR-132 regulates several targets involved in promoting or blocking neurite outgrowth and arborization.

Contradictory results are obtained with regard to the role of Mecp2 in neuronal development. Kish $\mathrm{N}$ et al. have proposed that MeCP2 mutation did not affect neural precursor proliferation and differentiation, suggesting it is mainly involved in neuronal maturation rather than cell fate determination [44]. However, several studies have demonstrated that ectopic expression of $\mathrm{MeCP} 2$ represses glial differentiation but promotes neuronal differentiation in mice $[45,46]$. Similar results are found in zebrafish that mecp2 knockdown increases neural precursors and gliogenesis, but impairs neurogenesis [47]. On the other hand, there are studies reporting that Mecp2 binds to astrocyte-specific marker GFAP and S100B to subsequently suppress their expression, and Mecp2 knockdown accelerates glial cell differentiation with elevated expression of GFAP $[48,49]$. In our study, the loss of Mecp2 promoted NSCs proliferation and glial cell differentiation. Interestingly, GFAP is also a downstream target of Notch signaling and Mecp2 could interact with Notch signal pathway to regulate cell proliferation and gliogenesis [47].

ERK1/2 signaling is crucial for neuronal proliferation, differentiation as well as neurite outgrowth [50]. It has been demonstrated that miR-132 up-regulation is related to ERK1/2 pathway activated by BDNF in differentiated neurons [51]. In our study, we found dramatically increased expression of miR-132 paralleling the activation of p-ERK1/2 during NSCs differentiation. When ERK1/2 was suppressed by SCH7729 84, we observed a clearly decrease in miR-132 expression and neuronal differentiation which was contrary to the effect of miR-132 in this process.

Stem cell behaviors like self-renewal and differentiation were quite complicated processes that involved activation of multiple signal pathways and their interaction with key molecules as well. In fact, this study also had yielded confused but interesting results. For instance, why inactivation of ERK1/2 pathway leading to decreased miR-132 


\section{Cellular Physiology Cell Physiol Biochem 2018;47:2319-2330 \begin{tabular}{l|l} 
and Biochemistry Published online: July 06, 2018 & $\begin{array}{l}\text { O) } 2018 \text { The Author(s). Published by S. Karger AG, Basel } \\
\text { www.karger.com/cpb }\end{array}$ \\
\cline { 2 - 3 } & POl:
\end{tabular} \\ Chen et al.: The Role of MiR-132 in NSCs}

expression impaired neuronal differentiation, but similar result was obtained in miR-132 overexpression? As one of the potential target genes of miR-132, why Mecp2 knocking down accelerated NSC proliferation while miR-132 mimics did the reverse? However, we couldn't exclude that MeCP2 may exert an inhibitory effect on miR-132 transcription in this process, since a feedback loop of miR-132, BDNF and Mecp2 had been proposed already [33], suggesting a homeostatic mechanism for maintaining MeCP2 at a certain level.

\section{Conclusion}

miR-132 was demonstrated as a negative regulator for NSCs self-renewal, neuronal differentiation but promoted glial cell differentiation and neurite outgrowth.

\section{Disclosure Statement}

The authors declare that they have no competing interests.

\section{References}

1 Gage FH: Mammalian neural stem cells. Science 2000;287:1433-1438.

-2 Wanet A, Tacheny A, Arnould T, Renard P: miR-212/132 expression and functions: within and beyond the neuronal compartment. Nucleic Acids Res 2012;40:4742-4753.

-3 Xu L, Mahairaki V, Koliatsos VE: Host induction by transplanted neural stem cells in the spinal cord: further evidence for an adult spinal cord neurogenic niche. Regen Med 2012;7:785-797.

4 Shi Y, Sun G, Zhao C, Stewart R: Neural stem cell self-renewal. Crit Rev Oncol Hematol 2008;65:43-53.

5 Ambros V: The functions of animal microRNAs. Nature 2004;431:350-355.

6 Bartel DP: MicroRNAs: genomics, biogenesis, mechanism, and function. Cell 2004;116:281-297.

-7 Meza-Sosa KF, Valle-Garcia D, Pedraza-Alva G, Perez-Martinez L: Role of microRNAs in central nervous system development and pathology. J Neurosci Res 2012;90:1-12.

8 Morgado AL, Xavier JM, Dionisio PA, Ribeiro MF, Dias RB, Sebastiao AM, Sola S, Rodrigues CM: MicroRNA34a Modulates Neural Stem Cell Differentiation by Regulating Expression of Synaptic and Autophagic Proteins. Mol Neurobiol 2015;51:1168-1183.

9 Shi X, Yan C, Liu B, Yang C, Nie X, Wang X, Zheng J, Wang Y, Zhu Y: miR-381 Regulates Neural Stem Cell Proliferation and Differentiation via Regulating Hes1 Expression. PLoS One 2015;10:e0138973.

10 Liu XS, Chopp M, Zhang RL, Tao T, Wang XL, Kassis H, Hozeska-Solgot A, Zhang L, Chen C, Zhang ZG: MicroRNA profiling in subventricular zone after stroke: MiR-124a regulates proliferation of neural progenitor cells through Notch signaling pathway. PLoS One 2011;6:e23461.

11 Biryukova I, Asmar J, Abdesselem H, Heitzler P: Drosophila mir-9a regulates wing development via finetuning expression of the LIM only factor, dLMO. Dev Biol 2009;327:487-496.

12 Bhinge A, Poschmann J, Namboori SC, Tian X, Jia Hui Loh S, Traczyk A, Prabhakar S, Stanton LW: MiR-135b is a direct PAX6 target and specifies human neuroectoderm by inhibiting TGF-beta/BMP signaling. EMBO J 2014;33:1271-1283.

$>13$ Boissart C, Nissan X, Giraud-Triboult K, Peschanski M, Benchoua A: miR-125 potentiates early neural specification of human embryonic stem cells. Development 2012;139:1247-1257.

14 Anderegg A, Lin HP, Chen JA, Caronia-Brown G, Cherepanova N, Yun B, Joksimovic M, Rock J, Harfe BD, Johnson R, Awatramani R: An Lmx1b-miR135a2 regulatory circuit modulates Wnt1/Wnt signaling and determines the size of the midbrain dopaminergic progenitor pool. PLoS Genet 2013;9:e1003973.

15 Edbauer D, Neilson JR, Foster KA, Wang CF, Seeburg DP, Batterton MN, Tada T, Dolan BM, Sharp PA, Sheng M: Regulation of synaptic structure and function by FMRP-associated microRNAs miR-125b and miR-132. Neuron 2010;65:373-384.

16 Hwang JY, Kaneko N, Noh KM, Pontarelli F, Zukin RS: The gene silencing transcription factor REST represses miR-132 expression in hippocampal neurons destined to die. J Mol Biol 2014;426:3454-3466. 


\section{Cellular Physiology Cell Physiol Biochem 2018;47:2319-2330 \begin{tabular}{l|l} 
and Biochemistry Published online: July 06, 2018 & $\begin{array}{l}\text { O 2018 The Author(s). Published by S. Karger AG, Basel } \\
\text { www.karger.com/cpb }\end{array}$ \\
\cline { 2 - 3 }
\end{tabular} \\ Chen et al.: The Role of MiR-132 in NSCs}

17 Luikart BW, Bensen AL, Washburn EK, Perederiy JV, Su KG, Li Y, Kernie SG, Parada LF, Westbrook GL: miR132 mediates the integration of newborn neurons into the adult dentate gyrus. PLoS One 2011;6:e19077.

18 Tognini P, Putignano E, Coatti A, Pizzorusso T: Experience-dependent expression of miR-132 regulates ocular dominance plasticity. Nat Neurosci 2011;14:1237-1239.

19 Im HI, Hollander JA, Bali P, Kenny PJ: MeCP2 controls BDNF expression and cocaine intake through homeostatic interactions with microRNA-212. Nat Neurosci 2010;13:1120-1127.

-20 Hollander JA, Im HI, Amelio AL, Kocerha J, Bali P, Lu Q Willoughby D, Wahlestedt C, Conkright MD, Kenny PJ: Striatal microRNA controls cocaine intake through CREB signalling. Nature 2010;466:197-202.

-21 Wang WX, Huang Q, Hu Y, Stromberg AJ, Nelson PT: Patterns of microRNA expression in normal and early Alzheimer's disease human temporal cortex: white matter versus gray matter. Acta Neuropathol 2011;121:193-205.

22 Vo N, Klein ME, Varlamova O, Keller DM, Yamamoto T, Goodman RH, Impey S: A cAMP-response element binding protein-induced microRNA regulates neuronal morphogenesis. Proc Natl Acad Sci U S A 2005;102:16426-16431.

23 Lungu G, Stoica G, Ambrus A: MicroRNA profiling and the role of microRNA-132 in neurodegeneration using a rat model. Neurosci Lett 2013;553:153-158.

24 Wong HK, Veremeyko T, Patel N, Lemere CA, Walsh DM, Esau C, Vanderburg C, Krichevsky AM: Derepression of FOXO3a death axis by microRNA-132 and -212 causes neuronal apoptosis in Alzheimer's disease. Hum Mol Genet 2013;22:3077-3092.

25 Soreq H, Wolf Y: NeurimmiRs: microRNAs in the neuroimmune interface. Trends Mol Med 2011;17:548555.

26 Park JK, Henry JC, Jiang J, Esau C, Gusev Y, Lerner MR, Postier RG, Brackett DJ, Schmittgen TD: miR-132 and miR-212 are increased in pancreatic cancer and target the retinoblastoma tumor suppressor. Biochem Biophys Res Commun 2011;406:518-523.

-27 Tian H, Hou L, Xiong YM, Huang JX, Zhang WH, Pan YY, Song XR: miR-132 targeting E2F5 suppresses cell proliferation, invasion, migration in ovarian cancer cells. Am J Transl Res 2016;8:1492-1501.

28 Luo J, Meng C, Tang Y, Zhang S, Wan M, Bi Y, Zhou X: miR-132/212 cluster inhibits the growth of lung cancer xenografts in nude mice. Int J Clin Exp Med 2014;7:4115-4122.

-29 Clovis YM, Enard W, Marinaro F, Huttner WB, De Pietri Tonelli D: Convergent repression of Foxp2 3'UTR by miR-9 and miR-132 in embryonic mouse neocortex: implications for radial migration of neurons. Development 2012;139:3332-3342.

-30 Taylor MK, Yeager K, Morrison SJ: Physiological Notch signaling promotes gliogenesis in the developing peripheral and central nervous systems. Development 2007;134:2435-2447.

-31 Salta E, Lau P, Sala Frigerio C, Coolen M, Bally-Cuif L, De Strooper B: A self-organizing miR-132/Ctbp2 circuit regulates bimodal notch signals and glial progenitor fate choice during spinal cord maturation. Dev Cell 2014;30:423-436.

32 Yang D, Li T, Wang Y, Tang Y, Cui H, Tang Y, Zhang X, Chen D, Shen N, Le W: miR-132 regulates the differentiation of dopamine neurons by directly targeting Nurr1 expression. J Cell Sci 2012;125:1673-1682.

-33 Klein ME, Lioy DT, Ma L, Impey S, Mandel G, Goodman RH: Homeostatic regulation of MeCP2 expression by a CREB-induced microRNA. Nat Neurosci 2007;10:1513-1514.

-34 Remenyi J, van den Bosch MW, Palygin O, Mistry RB, McKenzie C, Macdonald A, Hutvagner G, Arthur JS, Frenguelli BG, Pankratov Y: miR-132/212 knockout mice reveal roles for these miRNAs in regulating cortical synaptic transmission and plasticity. PLoS One 2013;8:e62509.

-35 Hancock ML, Preitner N, Quan J, Flanagan JG: MicroRNA-132 is enriched in developing axons, locally regulates Rasa1 mRNA, and promotes axon extension. J Neurosci 2014;34:66-78.

-36 Yoshimura A, Numakawa T, Odaka H, Adachi N, Tamai Y, Kunugi H: Negative regulation of microRNA-132 in expression of synaptic proteins in neuronal differentiation of embryonic neural stem cells. Neurochem Int 2016;97:26-33.

37 Breving K, Esquela-Kerscher A: The complexities of microRNA regulation: mirandering around the rules. Int J Biochem Cell Biol 2010;42:1316-1329.

38 Tognini P, Pizzorusso T: MicroRNA212/132 family: molecular transducer of neuronal function and plasticity. Int J Biochem Cell Biol 2012;44:6-10. 


\section{Cellular Physiology Cell Physiol Biochem 2018;47:2319-2330

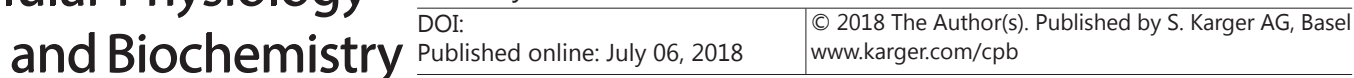 \\ Chen et al.: The Role of MiR-132 in NSCs}

-39 Nakazawa T, Watabe AM, Tezuka T, Yoshida Y, Yokoyama K, Umemori H, Inoue A, Okabe S, Manabe T, Yamamoto T: p250GAP, a novel brain-enriched GTPase-activating protein for Rho family GTPases, is involved in the N-methyl-d-aspartate receptor signaling. Mol Biol Cell 2003;14:2921-2934.

40 Godoy J, Nishimura M, Webster NJ: Gonadotropin-releasing hormone induces miR-132 and miR-212 to regulate cellular morphology and migration in immortalized LbetaT2 pituitary gonadotrope cells. Mol Endocrinol 2011;25:810-820.

41 Alvarez-Saavedra M, Antoun G, Yanagiya A, Oliva-Hernandez R, Cornejo-Palma D, Perez-Iratxeta C, Sonenberg N, Cheng HY: miRNA-132 orchestrates chromatin remodeling and translational control of the circadian clock. Hum Mol Genet 2011;20:731-751.

$>42$ Wayman GA, Davare M, Ando H, Fortin D, Varlamova O, Cheng HY, Marks D, Obrietan K, Soderling TR, Goodman RH, Impey S: An activity-regulated microRNA controls dendritic plasticity by down-regulating p250GAP. Proc Natl Acad Sci U S A 2008;105:9093-9098.

-43 Fukuda T, Itoh M, Ichikawa T, Washiyama K, Goto Y: Delayed maturation of neuronal architecture and synaptogenesis in cerebral cortex of Mecp2-deficient mice. J Neuropathol Exp Neurol 2005;64:537-544.

44 Kishi N, Macklis JD: MECP2 is progressively expressed in post-migratory neurons and is involved in neuronal maturation rather than cell fate decisions. Mol Cell Neurosci 2004;27:306-321.

45 Kohyama J, Kojima T, Takatsuka E, Yamashita T, Namiki J, Hsieh J, Gage FH, Namihira M, Okano H, Sawamoto K, Nakashima K: Epigenetic regulation of neural cell differentiation plasticity in the adult mammalian brain. Proc Natl Acad Sci U S A 2008;105:18012-18017.

-46 Tsujimura K, Abematsu M, Kohyama J, Namihira M, Nakashima K: Neuronal differentiation of neural precursor cells is promoted by the methyl-CpG-binding protein MeCP2. Exp Neurol 2009;219:104-111.

47 Gao H, Bu Y, Wu Q, Wang X, Chang N, Lei L, Chen S, Liu D, Zhu X, Hu K, Xiong JW: Mecp2 regulates neural cell differentiation by suppressing the Id1 to Her2 axis in zebrafish. J Cell Sci 2015;128:2340-2350.

-48 Okabe Y, Takahashi T, Mitsumasu C, Kosai K, Tanaka E, Matsuishi T: Alterations of gene expression and glutamate clearance in astrocytes derived from an MeCP2-null mouse model of Rett syndrome. PLoS One 2012;7:e35354.

49 Forbes-Lorman RM, Kurian JR, Auger AP: MeCP2 regulates GFAP expression within the developing brain. Brain Res 2014;1543:151-158.

50 Li Z, Theus MH, Wei L: Role of ERK 1/2 signaling in neuronal differentiation of cultured embryonic stem cells. Dev Growth Differ 2006;48:513-523.

-51 Kawashima H, Numakawa T, Kumamaru E, Adachi N, Mizuno H, Ninomiya M, Kunugi H, Hashido K: Glucocorticoid attenuates brain-derived neurotrophic factor-dependent upregulation of glutamate receptors via the suppression of microRNA-132 expression. Neuroscience 2010;165:1301-1311. 